Nidhomul Haq Vol 3 No: 1 Maret 2018

ISSN 2503-1481

\title{
تطوير المواد التعليمية لترقية مهارة الكتابة (بحث تطويري مع التطبيق في مدرسة أمانة الأمة الإعدادية فاجت موجوكرطا)
}

Muhammad Hafidz

Dosen Institut Pesantren KH Abdul Chalim Mojokerto

hafidz@ikhac.ac.id

\begin{abstract}
Abstrak
Ada banyak problem dalam proses belajar mengajar Bahasa Arab di Pondok Pesantren Amanatul Ummah Pacet Mojokerto, terutama dalam pembelajaran menulis. Diantara problem yang paling dominan adalah terjadinya kesalahan imla'.Untuk mengatasi masalah ini penulis mendesain bahan ajar untuk meningkatkan ketrampilan menulis bagi siswa.Dengan bahan ajar tersebut diharapkan siswa mampu menulis Bahasa Arab dengan benar sesuai dengan kaidah imla'.Atas dasar itulah penulis melakukan penelitian dengan metode penelitian dan pengembangan $(R \& D)$ dengan pendekatan kuantitatif dengan tujuan menghasilkan produk bahan ajar dan sekaligus menguji keefektifan produk tersebut.Instrumen penelitian yang digunakan adalah tes, angket dan wawancara. Setelah penulis mendesain bahan ajar, melakukan uji coba dan menganalisa seluruh data, penulis mendapatkan kesimpulan ; 1) Bahan ajar yang dihasilkan berupa bahan ajar yang memuat kaidah-kaidah penulisan Bahasa Arab, yaitu imla' mendapatkan penilaian tim ahli sebesar $79 \%$, artinya bahwa buku tersebut layak digunakan dalam pembelajaran . 2) Bahan tersebut sangat efektif untuk meningkatkan ketrampilan menulis bagi siswa, hal ini didasarkan pada hasil pretest dan posttest yaitu terdapt peningkatan yang cukup signifikan 20, $96 \%$ dari prosentase nilai pretest 62,2\% menjadi 83, $6 \%$ Dinilai posttest. Hal ini diperkuat dengan hasil analisa angket dan wawancara yang memiliki kesimpulan yang sama dengan analisaa nilai tes.
\end{abstract}

Kata kunci : Bahan Ajar, Pembelajaran Ketrampilan Menulis

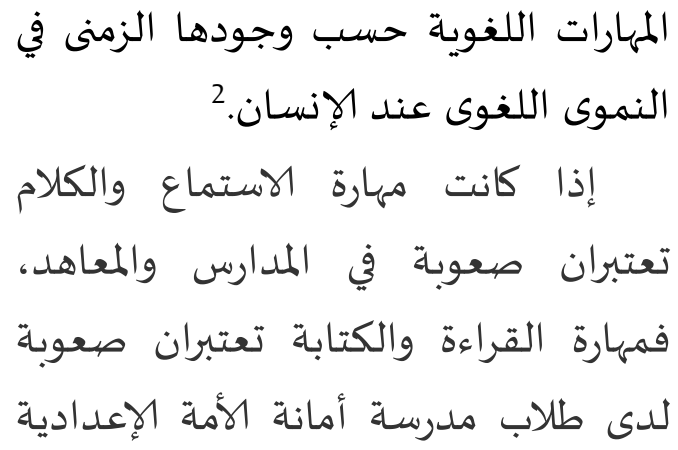

2 الشؤون المكتبات - جامعة الملك سعود، 1982)، 265.

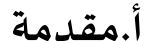

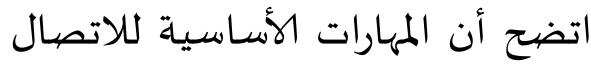

1 ـ . رشدي أحمد طعيمة، تعليم العربية لغير الناطقين بما:مناهجه

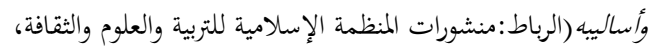
1989)، 
Nidhomul Haq Vol 3 No: 1 Maret 2018

ISSN 2503-1481

وكتابة التنوين نونا وما أشباء ذلك من

المشكالات الإملائية.

وتوجد أيضيا المشكلات العامة في

تعليم الإملاء منها اختلاف مستوى الطلاب اللغوي في الصف الواحد، لأنهم تخرجوا

من المدرسة الإبتدائية العامة و و من المدرسـة الإبتدائية الإسلامية فهه اختلطوا في فصل واحد، ثم عدم وجود كتب ومواد تعليمية مناسبة، وضعف دافعية الطلاب نحو تعلم اللغة العربية، لأن في والواقع، أكثر المادة التعليمية هي العلوم

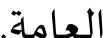

فيرى الباحث أن مشكلات الكتابة

المذكورة تسبب عن عدة أمور، ومنها : عدم وجود الكتاب المدرسي الخاص لمهارة الكتابة أو الإملاء للطالب وللمعلم. فجعلت عملية تعليم الكتابة تمر بحسب استطاعـة المعلم، بدون الكتاب وبدون الخطة الدراسية. حتى تصبح معرفة الطلاب لمهارة الكتابة بعيدة عن الكافة.

هذه هي مشكلات التي تحتاج حلولها، لأن الكتاب المدرسي هو أقدم المواد التعليمية وأهمها على الاطلاق، فهو بمثابة المرشد والمرجع لكل من المعلم والمتعلم، وفيا تحدد أهداف الموضع وطرائق تعليماه
فاجت موجوكرطا فضيلا عن مهارة الاستماع والكلام، لأن هذا المعهديهتم بمهارتى القراءة والكتابة كما يهتم بهما المعاهد التقليدية الأخرى. في هذا البحث يختار الباحث أن يبحث مهارة الكتابة، لأنها هي وسيلة من وسـائل الاتصال الانسانى، يتم عن طريقها

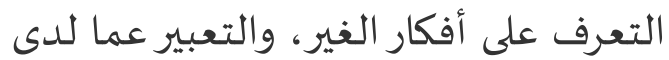
الفرد من معان ومفاهيم ومشاعر وتسجيل الحواديث والوقائع. وكثيرا ما يكون الخطأ الكتابى في الرسه، أو في عرض الفكرة، سبب في تغيير المعنى وعدم وضوح الفكرة.لذلك تعتبر الكتابة الصحيحة عملية مهمة في التعليم، إذ أهها عنصر أساسي في عناصر الثقافة، وضرورة اجتماعية لنقل الأفكار والتعبير عنها، والوقوف على أفكار وآراء الآخرين والإلمام لكن هناك مشكلات مهارة الكتابة، ومن أهمها الإملاء. حيث كتب الطلاب ما

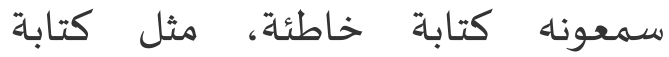
الكلمات ذات التشـديد ولا يستطيعون كتابة همزة الوصل وهمزة القطع وكتابة الهمزة في أول الكلمة وفي وسطها وآخرها

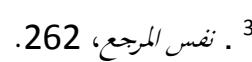


Nidhomul Haq Vol 3 No: 1 Maret 2018

ISSN 2503-1481

نظرا إلى مشكلات البحث التي سبق ذكرها، فأسئلة البحث هنا فيما يلى:1. كيف تصهيم المواد التعليمية لمهارة الكتابة في الإملاء الوظيفي؟،2. ما مدى فعالية المواد التعليمية المصهممة لتنمية مهارة الكتابة في الإملاء الوظيفي لدى

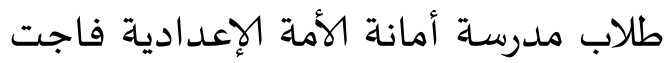

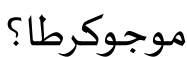
فأهداف البحث :الحصيول على المواد التعليمياة الجيدة لمهارة الكتابة في الإملاء الوظيفي،لمعرفة مدى فعالية تصيميم المواد التعليمية لمهارة الكتابة في الإملاء الوظيفي لدى طلاب مدرسة أمانة الأمة الإعدادية فاجت موجـوكرطا. ب. الطار النظري

\section{1. مفهوم المواد التعليمية}

المواد التعليمية هي المواد اللغوية التي تقدم لمتعلي اللغة، سواء أكانت مسموعة أو مقروءة، كالكتب بأنواعها،

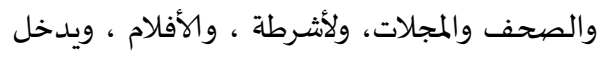
في ذلك الخطط والمناهج.6

وإعداد المواد التعليمية يعتبر من أصعب الأمور التي تواجه المسؤولين عن البرامج التعليمية وذلك لأن هذه العملية تحتاج إلى الماتي

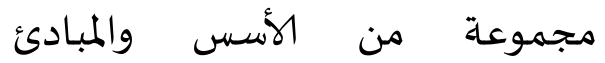

6 ـ . عبد العزيز إبراهيم العصيلي، طرائق تعليم اللغة العربية للناطقين بلغات أخرى (الرياض : مكتبة الملك فهد ، 2003) ، 243.
ويشير إلى (الأساليب التربوية المتبعة) والوسائل التعليمية الموافقة. 4 انطلاقا مما سبق، يحاول الباحث القيام بتطوير المواد التعليمية لمهارة الكتاباة، حلولا للمشكلات المذكورة. ورغم أن الكتاب المطبوع لمهارة الكتابة كثير من ناحية، إلا أن المواد التعليمية المناسبة للدارسين فمن قضيية من ناحية أخرى.5 إذ تصيميم المواد التعليمية مهمة ولها فوائد لطالب ولمعلم، منها : لمعلم : الحصول على مواد تعليمية مناسبة لنظام مقرر وزيادة معرفة معلم وخبرته في كتابة مواد تعليمية. وفوائد لطالب : نال طالب الخصية في تعلم ذاتي و السهل في تعلم كل المهارات أو كفاية لغوية التي تلزم فهمها. نظرا إلى المشكلات المذكورة سيبحث الباحث تحت العنوان "تطوير المواد التعليمية لترقية مهارة الكتابة " (بحث تطويري مع التطبيق في مدرسة أمانة الأمة الإعدادية فاجت موجوكرطا).

\footnotetext{
4 ـ ـممود إسماعيل صيني وعلي القاسمي، السجل العلمى للندوة

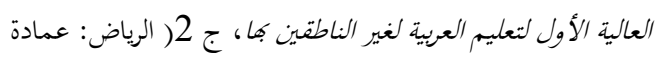
الشؤون المكتبات - جامعة الرياض، 1980)، 81.

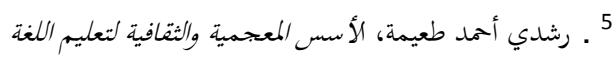

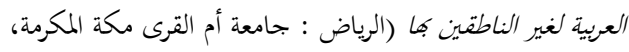
.7،(1982 
Nidhomul Haq Vol 3 No: 1 Maret 2018

ISSN 2503-1481

الخبرات وعرضها بشكل يتناسب

$$
\text { مع عرض الكاتب. } 9
$$

يفهه من هذا التعريف

الذي حدده رشدي أحمد طعيمة أن هندان

الكتابة بجانب أنها نشاط حركي فهي احمد فيه ان

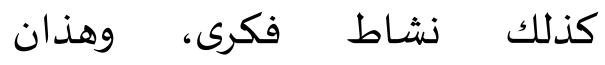

النشاطان معا يكونان المهارة الكلية

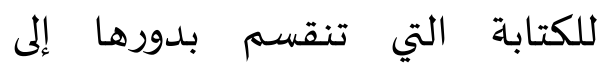

مهارتين : المهارة الحركية والمهارة

الفكرية العقلية. فالمهارة الحركية

تتمثل في جاني الهجاء والخط أي الهي

كتابة الحروف ثم كتابة الكلمات

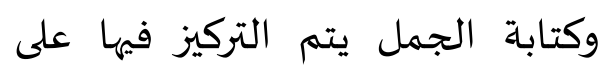

الرسم الكتابي لرموز اللغة وترتيب التملي فئ

هذه الرموز في تتابع كتابي كتتابعها

الصوتي. والمهارة الفكرية العقلية

تتمثل في جانبي التعبير والإنشاء أي

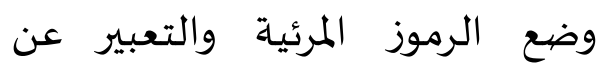

الأفكار في شكل مسلسل طبقا لنظام

تركيب اللغة والهدف النهائي من هذه

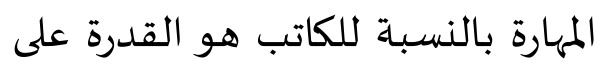

التعبير عن نفسها في صبغة مهذبة

9 و ـ رشدي أحمد طعيمة، المرجع في تعليم اللغة العربية للناطقين

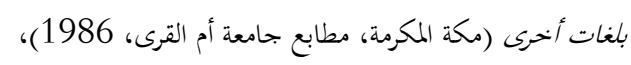

والشروط التي بدونها تصبح عملية غير عملية

تأتي مواد التعليم لتكمل

عناصر التعلّم الثلاثة: معلم ومتعلم

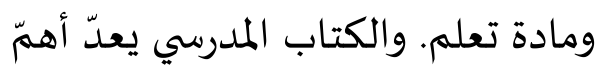
موادّ التعليم؛ ومن هنا فإنّ المربّين

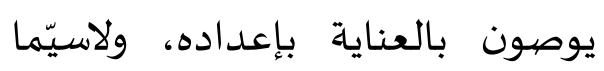
تلك الموادّ التي تعنى بتعليم اللغنة العربية لغير الناطقين بها.7

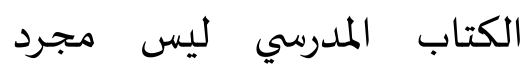
وسيلة معينة على التدريس فقط، وإنما هو صلب التدريس وأساسـ لأنه

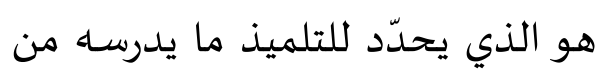

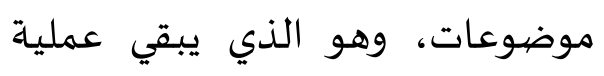

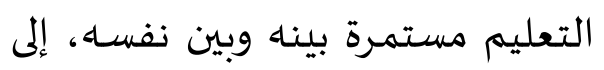

$$
\text { أن يصل منها إلى ما يريد.8 }
$$

عرف رشدي أحمد طعيمة الكتابة بأهها : نشاط ذهني يعتمد

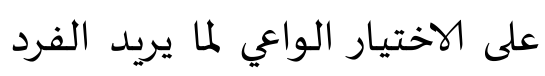

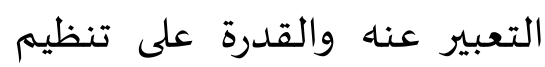

$$
\begin{aligned}
& 7 \text { 7 . عبد الرحمن بن إبراهيم الفوزان، إعداد مواد تعليم اللغة العربية }
\end{aligned}
$$

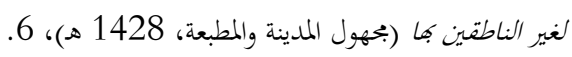

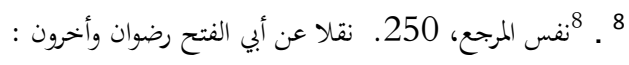

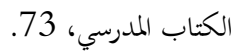


Nidhomul Haq Vol 3 No: 1 Maret 2018

ISSN 2503-1481

استحال فهم المعاني والأفكار التي تشتمل عليها.

إذا لا يضيق مفهوم الكتابة

على تدريس الطلاب على النسخ والتهجئة ولكن تتسع بتنمية قدرة

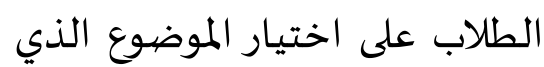

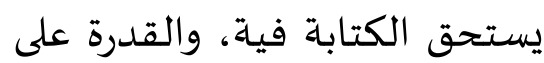
تنظيماه، وعرضها بطريقة مقنعة ومشوقة في آن واحد.

بنسبة ما ذكر من تركيز

تعليم الكتابة فيركز الباحث هنا على بحث الكتابة إملائيا.

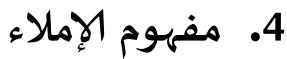

للإملاء أهمية خاصية في اللغة

العربية وذلك لما يترتب على الخطأ الإملائي في تغير في صورة الكلمة الذي بدوره يؤدى إلى تغير في في معناها.11 فذلك كانت فروع اللغة بدودي العربية كلها تعتمد إليه. وأن إتقان هذه المهارة يساعد على فهم المربيان

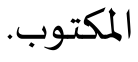

10 وأسالييه، 186. 11 . نايف معروف، خصائص العربية وطرق تدريسها (بيروت : دار النفائس، 1997)، 165-166.
راقية تنطلب الاستخجام الفعال للثروة اللفظية وسائر تراكيب اللغة 3. طبيعة الكتابة وأهميتها الكتابة وسيلة من وسائل الاتصال اللغوي بين الأفراد، مثلها في ذلك مثل الاستماع والكلام والقراءة. إنها كما نعلم ضرورة إجتماعية لنقل الأفكار. والوقوف على أفكار الآخرين على امتداد الهاد بعدي الزمان والمكان. وتركز تعليم الكتابة في العناية بثلاثة أمور : أ) قدرة الدارسين على الكتابة الصحيحة إملا ئيا، ب) وإجادة الخط، ج) وقدرتهم على التعبير عما لديهم من أفكار في وضوح ودقة.

أي لا بد أن يكون الدارس

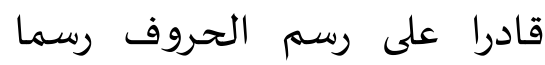
صحيحا، وإلا اضطربت الرموز، واستحالت قراءها. وأن يكون قادرا على كتابة الكلمات بالطريقة التي اتفق عليها أهل اللغة، وإلالا تعذرت ترجمتها إلى مدلولاتها. وأن يكون قادرا على اختيار الكلمات ووضعها في تظام خاص، وإلا 
Nidhomul Haq Vol 3 No: 1 Maret 2018

ISSN 2503-1481

طبقا للموضيوع الذي قدماه الباحث

وهو تطوير المواد التعليمية لترقية مهارة

الكتابة فينطلق هذا البحث من المدخل

الكمي. لأن الباحث سيتخدم في بحثـا

أدوات البحث لجميع البيانات وتحليل

بحثه تحليلا إحصائيا.14 أما نوع البحث البحان

فهو البحث التطويري، أو البحث

والتطوير (Research and )

(Development / R \& D

البحث المستخدم للحصول على الانتاج

الجـديد بطريقة التطوير، وأما خطوات

التطوير الأساسية فهي : تحليل

الاحتياجات و و تخطيط والتجريبي

الميداني وتطوير الانتاج وتحكيم الخبراء

ثم التصحيح والتعديل. 15

2.تصيميم البحث

يجري الباحث تجربته على تصهيم

مجموعة واحدة بالاختبار القبلي

One group pretest and والبعدي)

) ويستخدم هذا

التصيميم لمعرفة أثر أو فعالية المتغير

14 . Sugiono,

MetodePenelitianPendidikanPendekatanK uantitatif, Kualitatifdan $R \& B$ (Bandung : Alfabeta, 2012), 14.

15 . EndangMulyatiningsih,

MetodePenelitianTerapanBidangPendidik

an(Bandung :Alfabeta,2012), 50.
الإملاء هو تحويل الأصيوات

المسموعة المههومة إلى رموز

مكتوبة (الحروف) على أن توضع

هذه الحروف في مواضعها

الصحيحة من الكلمات وذلك له

لاستقامة اللفظ وظهور المعنى

المراد.12 يتضشمن هذا التعريف

مرحلة الكشف عن قدرة المتعلم

على كتابة ما يسمح.

5. المشكلات الإملائية

تعليم الإملاء لغير العرب

وبالأخص ماب مابو للطاب

الإندونيسيين ، يواجـه الصعوبات

والمشكلات. وهذه الصعوبات منها

ما هو بسبب رسم الحروف

العربية ، ومنها ما بسبب الحركات

التي توضع على هذه الحروف

سواء كانت في بنية الكلمات أم

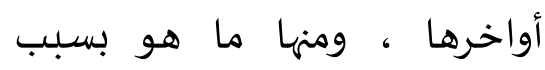

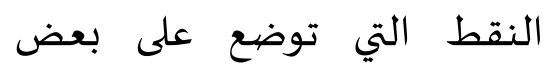

الحروف.13

ج. منهجية البحث

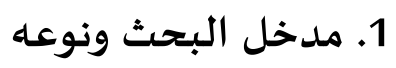

$$
\begin{aligned}
& 12 \text {. المرجع نفسه. } \\
& 13 \text { ـ أحمد فؤاد محمود عليان ، المهارات اللغوية ماهيتها وطرائق } \\
& \text { تدريسها (الرياض : دار المسلم، 1992)، 158-162. }
\end{aligned}
$$


Nidhomul Haq Vol 3 No: 1 Maret 2018

ISSN 2503-1481

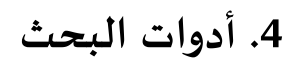

يستخدم الباحث لإجراء وإنجاز بحثه

$$
\text { ولتحقيق هدفه أدوات تالية : }
$$$$
\text { إن أدوات جمع البياناتهنا فيمايلي: }
$$

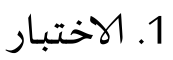

وهو مجموعة من الأسئلة التي يطلب التبار

من الدارس أن يستجيب لها بهدف

قياس مستواه في مادة معينة وبيان

مدى تقدمه فيها ومقارنته بزملائه. 18

يستخدم الباحث الإختبار القبلي

والبعدي لمعرفة مدي فعالية المواد

التعليمية في تنمية مهارة الطلاب في

كتابة اللغة العربية، حيث إن نتائج

الاختبار القبلي تكشف عن مقدرة

الطلاب قبل تجربة المواد التعليمية،

ونتائج الاختبار البعدي تكشف عن

$$
\text { قدرتهم بعد تجربها. }
$$

2. - الاستبانة

وهي أداة تتضمن مجموعة من الأن الرسئة

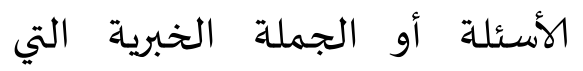

يطلب من المفحوص الاجابة عنها

بطريقة يحددها الباحث حسب البن الهن

18 ـ رشدي أحمد طعيمة، المرجع في تعليم اللغة العربية للناطقين

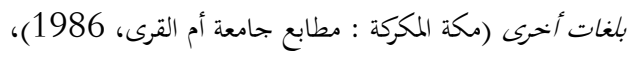

المستقيل (تصميم المواد التعليمية )

في المتغير التابع16 (تنمية مهارة

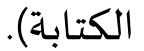

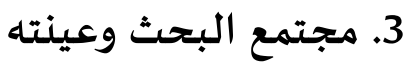

فمجتمع البحث هنا هو جميع

تلاميذات مدرسة أمانة الأمة

الإعدادية الفصل الثامن (ج) فاجت

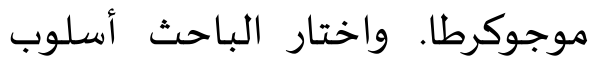

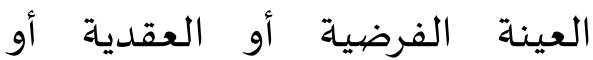

الهدفية (Porposive sample)واختار

هذا النوع من العينات لتحقيق

غرضاه، بحيث يقدر حاجاته من هن الن النينات

المعلومات، ويقوم باختيار عينة

الدراسة اختيارا حرا، على أسساس أهنا

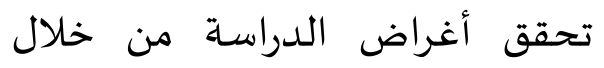

توافر البيانات اللازمة للباحث في

أفراد هذه العينة. 17 واختار الباحث

العينة المناسبة لأغراض دراستاه وهي

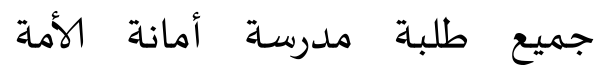

الإعدادية الفصل الثامن (ج) فاجت

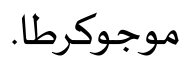

${ }^{16}$. Moh.Ainin,

MetodologiPenelitianbahasa Arab

(Surabaya :HilalPustaka, 2010), 88.

$$
\text { وممارسته العملية (دمشق : دار دويد الفكر، العلمي : 2008)، أساسيته النظرية }
$$


Nidhomul Haq Vol 3 No: 1 Maret 2018

ISSN 2503-1481

عن التفاوت أو المساوة بين

حالتين أو معاملتين على الماولى

أسـاس المقارنة بين الوسط

الحسابي أو المعدل (mean)

من الحالتين.

ويتم إجراء تحليل البيانات

بهذا الاختبار من ملاءل

الخطوات الاخصيائية

التالية 22 :

أولا : جدول نتائج الاختبار

القبلي والبعدي وتفاوتها على

$$
\text { النحو التالي : }
$$

جدول نموذج جدول نتائج الاختبار

القبلي والبعدي والتفاوت بينها :

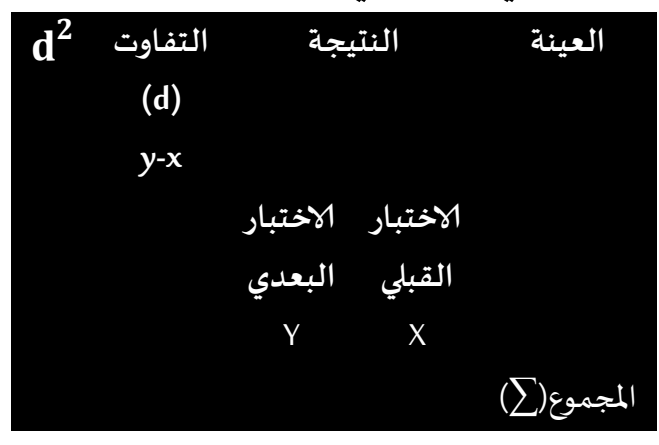

ثانيا : تعين معدل التفاوت

بين الاختبارين. ورمزه كما يلي

${ }^{21}$. M. Subana\&sudrajat, DasardasarPenelitianIlmiah (Bandung :PustakaSetia, 2001), 158.

22 . Ibid, hal. 156-157.
أغراض البحث.19 واختار الباحث

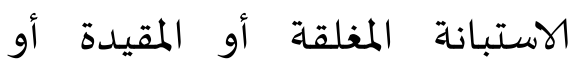

محدودة الخيارات، حيث يطلب من اهن

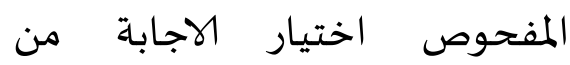

الاجابات الموجودة وليستخدم

الباحث هذه الأداة لمساندة البيانات

التي يحصل عليها من خلال الاختبار.

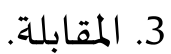

وهي محادثة موجهة بين الباحث

وشخص أو أشخاص آخرين بهدف مئه

الوصهول إلى حقيقة أو موقف معين،

يسعى الباحث للتعرف عليه من أجل تحقيق

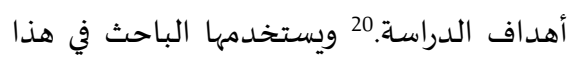

البحث كأداة ثانوية إضافية لتعزيز ما حصلت عليه الأدتان السابقتان.

\section{5. طريقة تحليل البيانات}

يستخدم الباحث لتحليل البيانات

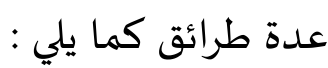

أ) - "اختبار t tes ) "t tes لتحليل

البيانات التي يحصل عليها

الباحث خلال الاختبار

القبلي والبعدي. هذا

الاختبار يستخدم للاكتشاف

19

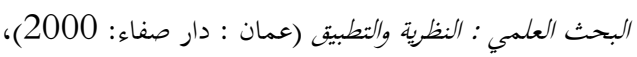

82

20 . . رجاء زحيد دويدري، البحث العلمي، 323. 
Nidhomul Haq Vol 3 No: 1 Maret 2018

ISSN 2503-1481

جدول" فهناك تميز أو هناك فعالية

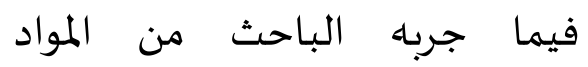

التعليمية. وإذا كان عدد "t حساب"

$\mathrm{Md}=\frac{\sum d}{n}$

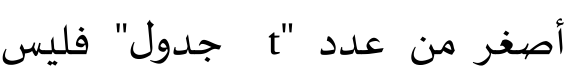

هناك تميز أو ليس هناك فعالية فيما

جرباء منها.

ب) تحليل البيانات من الاستبانة

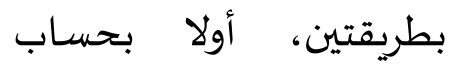

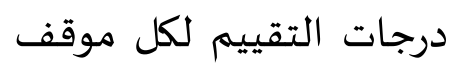

يختاره الطالب. ثانيا بتعيين

النسبة المئوية ومقارنتها.

ويستخدم الباحث في هذا

البحث الاستبانة على نهاجي

مقياس ليكرت (likkert).

وشكل الاستبانة مغلقة أو لورت مقات

مقيدة حيث يطلب من من المان

الطالب الاجابة من الإجابات

الموجودة فيها. وتقييم

الدرجات كما يلي :

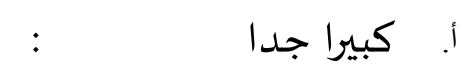

2

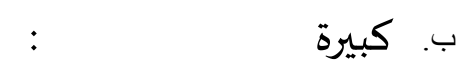

1

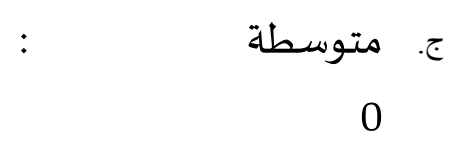

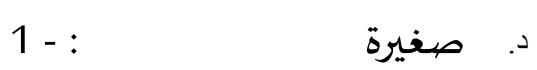


Nidhomul Haq Vol 3 No: 1 Maret 2018

ISSN 2503-1481

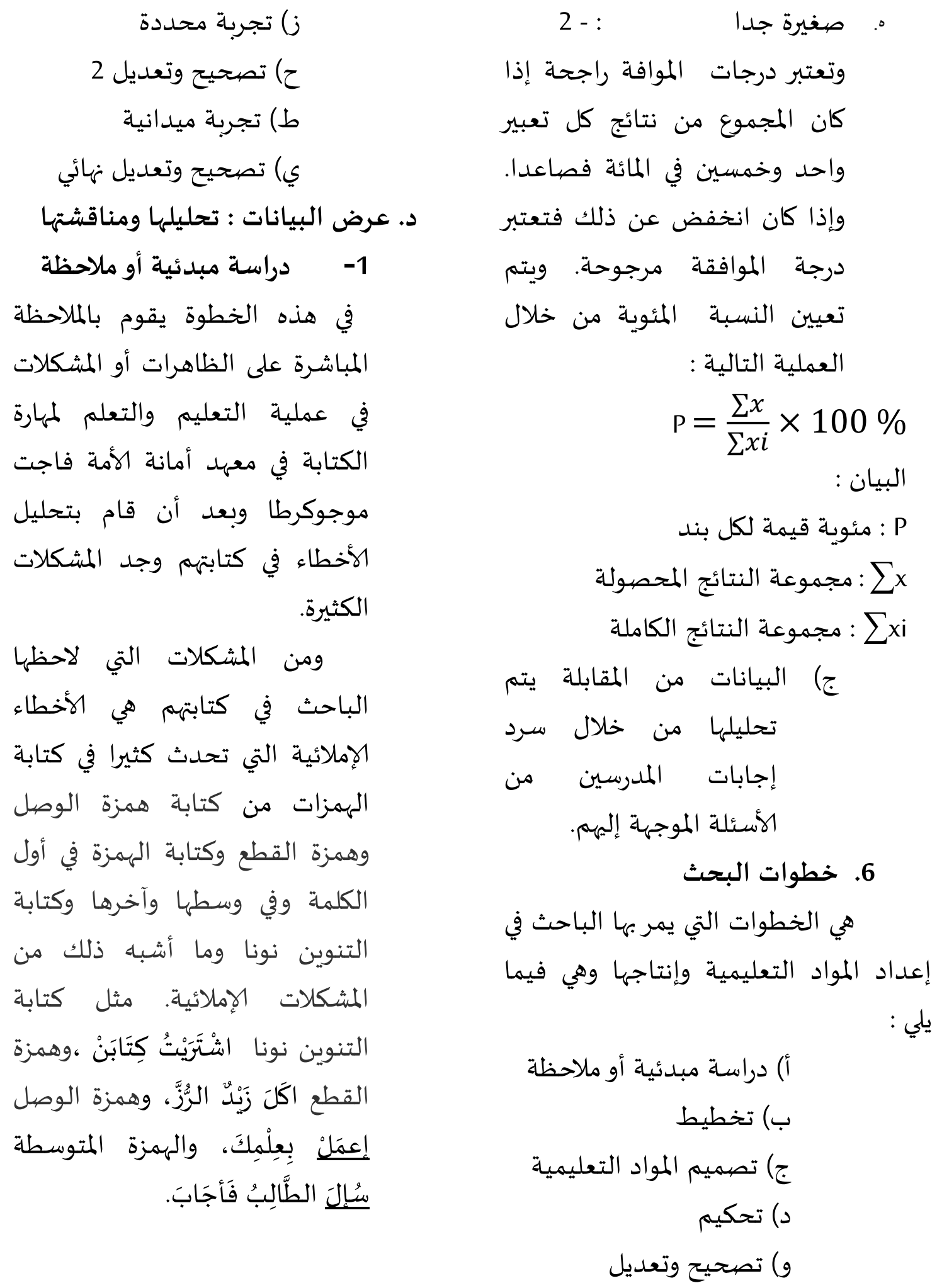


Nidhomul Haq Vol 3 No: 1 Maret 2018

ISSN 2503-1481

وفيما يلي صورة الكتاب المصيمم على

سبيل التفصيل :

4. تحكيم

جرت عملية التحكيم من10-17

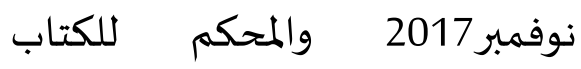
المصمم هو الخبير المتأهل والمتخصص في اللغة العربية وتعليمها، هو الدكتور نصر الدين إدريس جوهر، هو المخاضر في جامعة سونن أمبيل الإسلتمية

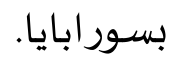

إن المعايير لتقويم وتحكيم الكتاب المصهمم تتكون من أربعة مجالات رئيسية : ملائمة محتويات الكتاب، واللغة، وعناصر استخدام الكتاب، ورسوم تخطيطية. جدول درجة النجاح

لعملية التقييم

1.

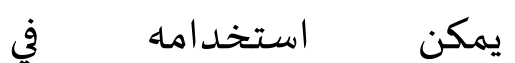
التدريسبدون التصحيح والتعديل

2.

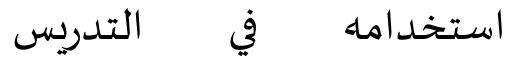

بالتصحيح والتعديل البسيط
انطلاقا من هذه المشكلات

فالطلاب في حاجة ماسة إلى كتاب

تعليمي يحتوى على القواعد الإملائية الأساسية باللغة التي سهلت مفهومها وفيها أمثلة كثيرة.

2. تخطيط

اعتمادا على حاجات الطلاب فخط الباحث لتصيميم الكتاب التعليمي لمساعدة الطلاب في استخدام اللغة

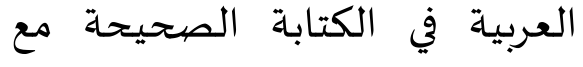
مراعاة القواعد الكتابية والإملائية. ويكون الكتاب للمستوى المتوسط ويحتوى على معظم قواعد الإملاء العربية التي أخطأ فيها كثير من فواعد الإماء الطلاب ويستخدم الكتاب أنواعا مختلفة ومتعددة من التدريبات.

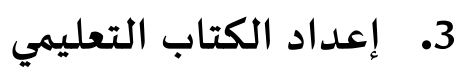
انطلق تصميم الكتاب من حاجات

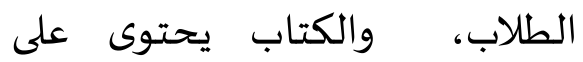
القواعد الإملائية. والكتاب كما ذكره الباحث في الفصل الثالث يتكون على جزء واحد ويتكون من ستة دروسا، ويحتوي كل درس على ولى لهاء الأمثلة المتعلقة بقواعد الإملاء والشرح والتدريبات ثم الخلاصة. 
Nidhomul Haq Vol 3 No: 1 Maret 2018

ISSN 2503-1481

نظرا إلى النتائج كلها فيكون تقدير

الكتاب المصيمم مقبول يقرب بالدرجة جيد وصادق بالدرجة 79 \% ومعنى ذلك

أنه يمكن استخداماه في التدريس بالتصحيح البسيط.

والكتاب وإن كان يمكن في التدريس

بتصحيح، فأوصى المحكم بتصحيح بعض الأمور وإتمامها وقي فيما يلي :

أ. زيادة الأهداف في لئي كل

درس لأن الكتاب ليس

$$
\text { فيا الأهداف لدرن }
$$

$$
\text { ب. رسـوم تخطيطية }
$$

5. تصحيح وتعديل 1

بعد أن تم تحكيم الخبير فأسرع

الباحث إلى تصحيح وتعديل ما

وجده من الأخطاء والنقصان في

الكتاب المصيمم حتى يكون

الكتاب في أكمل صورته. ويكون

الكتاب بعد التصحيح تمام

الأهداف في كل درس وجمال

$$
\text { الرسوم التخطيطية. }
$$

6. تجربة محددة

جرت تجربة محددة مع زمرة قليلة من الطلاب الفصل الثامن

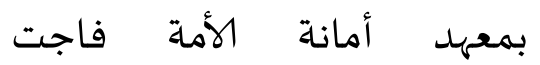

موجوكرطا مع توزيع الاستبانة
3.

يمكن استخدامه في التدريس

4.

كله أويبدل

ونتائج تحكيم الخبير

للكتاب المصيمم هي :

أ) ملائمة محتويات الكتاب حصلت

على النتيجة 83 \% وعلى حسب

المقياس المستخدم فدخلت هذه

النتيجة في أعلى درجة فالتقديرلها

جيد وصيادق

ب) اللغة ملائمة محتويات الكتاب

وحصلت على النتيجة 90 9

وعلى حسب المقياس المستخدم

فدخلت هذه النتيجة في أعلى

درجة فالتقدير لها جيد وصيادق

ج) عناصر استخدام الكتاب ملائمة

محتويات الكتاب وحصلت على

النتيجة 63 \% وعلى حسب

المقياس المستخدم فدخلت هذه

$$
\text { النتيجة مقبول }
$$

د) رسوم تخطيطية ملائمة محتويات

الكتاب وحصلت على النتيجة 80

\% وعلى حسب المقياس المستخدم

فدخلت هذه النتيـجة مقبول. 
Nidhomul Haq Vol 3 No: 1 Maret 2018

ISSN 2503-1481

and posttest design

إجراء الاختبار القبلي في 7 من

أغسطس 2017، ونوع الاختبار

وهو الاختبار التحريري حيث أمر الغربـ

مدرس الطالبات أن يكتبن

الكلمات التي فيها أنواع الهمزات

والتنوين والتشديد والن القمرية

والشمسية. ومعيار التقويم هو ولان

صحة الكتابة صحة إملائية.

يستخلص الباحث من البيانات

$$
\text { المعروضة ما يلي : }
$$

1- أعلى نتيجة حصل عليها

$$
\text { بعض الطلاب = معرل } 80
$$

2- معدل النتائج = 1555 :

$$
2 ، 62=25
$$$$
\text { 3- }
$$

. $62 \times \% 100=\frac{1555}{2500}$

2

وبعد إجراء الاختبار القبلي أجرى

الباحث تجربة الكتاب المصيمم في الفصل من 7 من سبتمبر 2017 إلى 10 من أكتوبر 2017 ثم سم أجرى الاختبار البعدي في 27 من اكنوبر

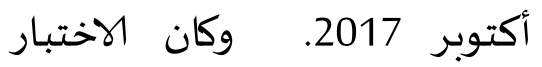
البعدي بنفس النوع والسؤال المستخدم في الاختبار القبلي.
المغلقة عليهم. والنتيجة من هذه

العملية هي أن الكتاب فعال

لتنمية مهارة الطلاب في كتابة

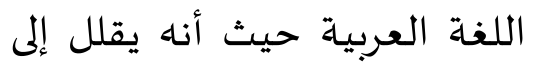

حد كبير أخطاءهم الإملائية.

\section{7. تصحيح وتعديل 2}

بعد أن جرت التجربة

المحددة وجد الباحث الأخطاء

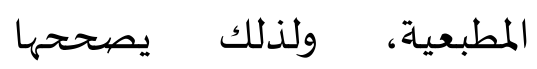

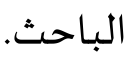

هذه هي نتائج البحث من خطوات تصميم المواد التعليمية ويليها سيعرض الباحث نتائج البحث من تجربة المواد التعليمية الميدانية.

هـ. تجربة المواد التعليمية الميلة

ذكر الباحث أن هذا البحث ينطلق من

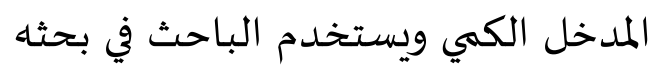
الأدوات : الاختبار والاستبانة والمقابلة لجمع البيانات وتحليل بحثه ولتحقيق هدفه. ونتائج البحث من الأدوات فيما يلي :

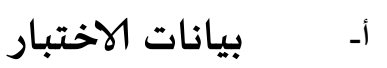

إن تصميم البحث هو تصميم مجموعة واحدة بالاختبار القبلي والبعدي( Onetest group prete 
Nidhomul Haq Vol 3 No: 1 Maret 2018

$$
\begin{aligned}
& \text { فمعدل التفاوت (Md =) فئ } \\
& 96 \text { 21 = } 25: 549
\end{aligned}
$$

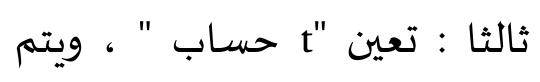

$$
\begin{aligned}
& \text { من خلال العملية التالية : } \\
& t=\frac{M d}{\sqrt{\frac{\sum d^{2}-\frac{\left(\sum d\right)^{2}}{n(n-1)}}{n}}} \\
& t=\frac{21,96}{\sqrt{\frac{13411-\frac{549^{2}}{25}}{25(25-1)}}} \\
& t=\frac{21,96}{\sqrt{\frac{13411-12056,04}{600}}} \\
& t=\frac{21,96}{\sqrt{2,25}} \\
& t=\frac{21,96}{1,5} \\
& \text { = حساب t" } \\
& 14,64 \\
& \text { رابعا " جدول }
\end{aligned}
$$

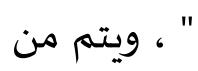

$$
\begin{aligned}
& \text { خلال العملية } \\
& \text { التالية : } \\
& \begin{array}{r}
\mathrm{t}=\left(1-\frac{1}{2} \propto\right. \\
)(n-1)
\end{array}
\end{aligned}
$$

$$
\begin{aligned}
& \text { يستخلص الباحث من البيانات } \\
& \text { المعروضة ما يلي : الباحت }
\end{aligned}
$$

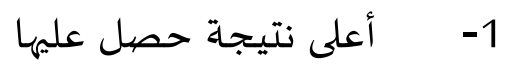$$
\text { الدارس =95 وأخفضها }
$$$$
60=
$$$$
\text { 2- معدل النتائج =2104: }
$$$$
16 ، 84=25
$$$$
\text { 3- }
$$$$
\text { . } 84 \times \% 100=\frac{2104}{2500}
$$$$
\% 16
$$

وتتضح من النتائج

المذكورة بين اختئار

القبلي والمتتبار البعدي

تنمية الطلاب في كتابة

اللغة العربية مع مراعاة

قواعد الإملاء، حيث أن الن مراعاة

درجة معدل الطلاب عند

الاختبار القبلي 62، 2 \%

وعند الاختبار البعدي 84،

. \% 16

ثانيا : تعيين معدل التفاوت بين

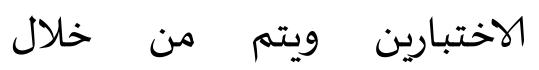

المعادلة التالية :

$\mathrm{Md}=\frac{\sum d}{n}$ 
Nidhomul Haq Vol 3 No: 1 Maret 2018

ISSN 2503-1481

وهذه النتيجة من الاختبار تؤكد

أن الكتاب التعليهي - وهو أهم

مواد التعليم - عنصر مهم من

عناصر التعلم الثلاثة وركن من من من

أركان عملية التعلم وهو ليس

مجرد وسيلة ومعينة على

التدريس فقط وإنما هو صلب ومعيل

التدريس وأساسـ لأناه هو الذي هو هولي

يحدد للطالب ما يدرسه من

موضوعات، ولذلك على المعلم أن من لئ

يصمم كتابا تعليميا لنجاح ولني المعلمان

عملية التعلم والتعليم.

$\left(1-\frac{1}{2} 0,01\right)(25-$

$$
\text { عملية التعلم والتعليم. (- مئ. }
$$

$$
\text { ز. نتائج البحث }
$$

لقد تم تصميم المواد التعليمية وقد

قام الباحث بتجربتها وتحليل البيانات

منها ومناقشتها فيستنتج ما يأتي :

1-

من خلال الكتاب التعليميي

يحتوي على القواعد الإملائية.

$$
\mathrm{t}=0,12
$$

خامسا : التحليل الأخير هو إذا

كان عدد" t حساب " أكبر من

عدد "t جدول " فهناك تميز أو

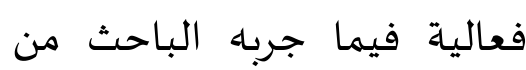

t" المواد التعليمية، وإذا كان عدد البهاحد

حساب " أصغر من عدد "

جدول " فليس هناك تميز أو

فعالية فيما جربة منها.

وبالنظر إلى

نتائج العملية

السابقة تبين

$$
\begin{aligned}
& \text { أن : } \\
& \text { " حساب " t" } \\
& \text { 14، } 64 \\
& \text { " جدول t " }
\end{aligned}
$$

والكتاب تحت العنوان :

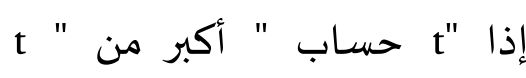

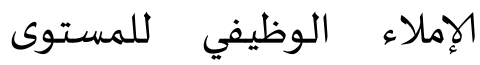

جدول "، ومعنى ذلك هناك تميز

المتوسط، وحصل على تقدير

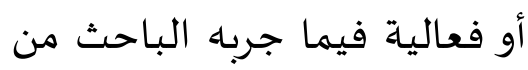

مقبول من عملية تحكيم

المواد التعليمية لتنمية مهارة

الخبير بالدرجة المئوية 79 \% .

الكتابة عند الطلاب. 
Nidhomul Haq Vol 3 No: 1 Maret 2018

ISSN 2503-1481

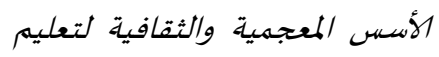

اللغة العببية لغير الناطقين به.الرياض:

جامعة أم القرى مكة المكرمة، 1982.

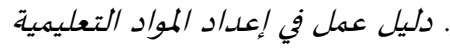

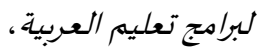

• عليان، رجي مصطفى. و عثمانمحمد غنيم. مناهج وأساليب البحث العلمي : النظرية والتطبيق. عمان : دار صفاء، 2000.

عليان، أحمد فؤاد محمود.المهارات اللغوية ماهيتها وطرائق تدريسها. الرياض : دار المسلم، مولهودئ.

1992

عبد المجيد، جابر وآخرون. مناهج البحث في التربية وعله النفس. القاهرة: دار النهضية

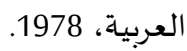

عصيلي (ال) عبد العزيز إبراهيم. طرائق تعليم اللغة العببية للناطقين بلغات أخرى. الرياض : مكتبة الملك فهد ، 2003.

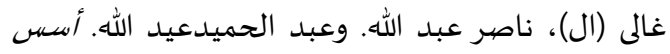

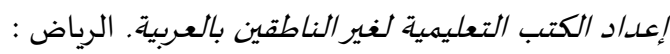

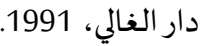

فوزان (ال)، عبد الرحمن بن ابراهيم. دروس الدورات

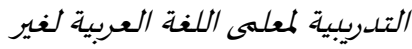

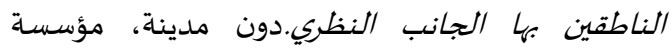
الوقف الإسلامي، 1423.

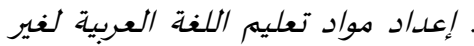

الناطقين بها (مجهول المدينة والمطبعة، 1428 هـ

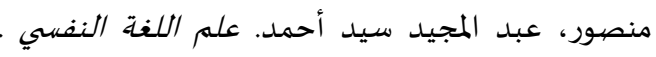
الرياض: عمادة الشؤون المكتبات جامعة الملك سعود، 1982.

معروف، نايف.خصيائص العربية وطرق تلدريسها. بيروت

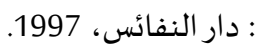

ناقة (ال) محمود كامل. ورشدي أحمد طعيمة. الكتاب الأساسي لتعليم اللغة العبربية للناطقين بلغات أخرى. مكة المكرمة : جامعة أم القرى، 1983.
واستخدامه في عملية التعليم والتعلم صالح.

2- المواد التعليمية المهمة

فعالة لتنمية مهارة الطلاب في

كتابة اللغة العربية مع مراعاة

قواعد الإملاء حيث أن درجة

معدل الطلاب عند الاختبار

القبلي 2، 62 \% وعند الاختبار

البعدي 84، 16 \% وأكدت

ذلك نتيجة الاستبانة والمقابلة.

\section{قائمة المراجع}

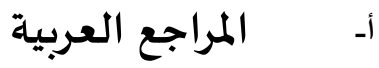

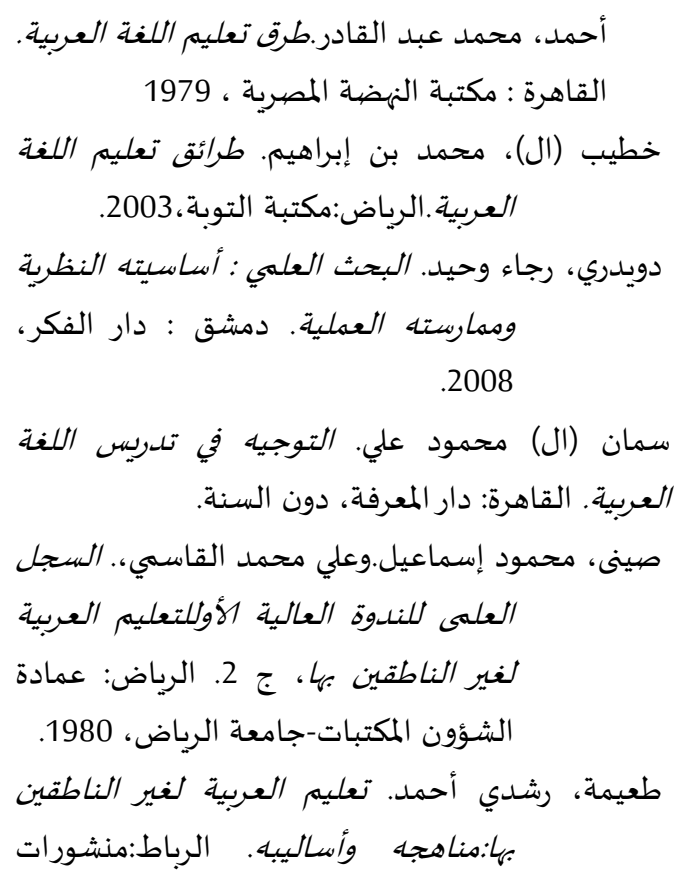
المنظمة الإسلامية للتربية والعلوم والثقافة،

.1989 
Nidhomul Haq Vol 3 No: 1 Maret 2018

ISSN 2503-1481

Suyanto, Kasihani K.E. English For Young learning. Jakarta: bumi Aksara, 2007.

Sugiono.Metode Penelitian Pendidikan pendekatan Kuantitatif, Kualitatif dan $R \&$ B. Bandung: Alfabeta, 2012.

Subana, M. \& sudrajat. Dasar-dasar Penelitian Ilmiah. Bandung: Pustaka Setia, 2001.

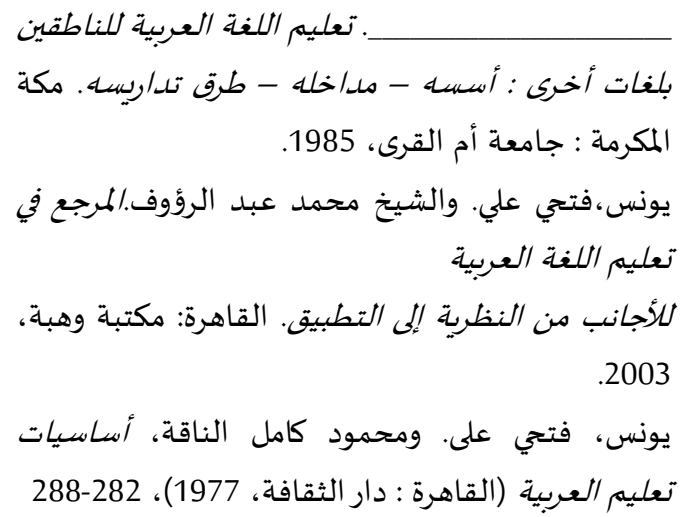

Arikunto, Suharsimi. Prosedur Penelitian Suatu Pendekatan Praktek. Jakarta: PT. Rineka Cipta, cet. 13,2006.

Arifin, Zainal, Penelitian Pendidikan: Metode dan paradigm Baru. Bandung: Remaja Rosdakarya, 2011.

Ainin, Mohammad. Metodologi Penelitian Bahasa Arab.Surabaya: Hilal Pustaka, 2010.

Diwandono, M. Soenardi. Tes Bahasa dalam Pengajaran. Bandung: ITB. 1996.

Mulyatiningsih, Endang. Metode Penelitian Terapan Bidang Pendidikan. Bandung: Alfabeta, 2012.

Sujana, Nana. Dasar-dasar proses belajar mengajar. Bandung: Sinar Algensindo, 2000. 